\title{
La afectividad en el aula preescolar: Reflexiones desde la práctica profesional docente
}

\author{
Affectivity in the Preschool Classroom: Reflections from Teaching
}

\author{
Carmen María Villalobos González \\ Ministerio de Educación Pública, Escuela Invu Las Cañas \\ Alajuela, Costa Rica \\ villagon03@gmail.com
}

Recibido 6 de julio de 2013 • Corregido 24 de octubre de 2013 • Aceptado 6 de noviembre de 2013

Resumen. Este ensayo reflexiona acerca de las experiencias docentes que permiten trascender en la niñez que se atiende y crecer como persona y como profesional. La autora aborda el tema de la afectividad positiva hacia el estudiantado, lo que permite en los niños y las niñas el ajuste emocional y la consecuente promoción de deseos de aprender, de asistir a clases y las buenas relaciones sociales con sus iguales; en el personal docente, confianza y una fuerte autoestima. Se enfatiza en quien educa debe dar un buen trato a sus estudiantes, conocer su entorno familiar, suplir las carencias afectivas -si las hubiera- y mostrar empatía hacia ellos. En síntesis, se motiva al personal docente a privilegiar las relaciones afectivas en su práctica pedagógica. También la autora incluye algunas experiencias derivadas de su práctica profesional, donde la afectividad hacia el niño fue esencial.

Palabras claves. Niñez, afecto, ternura, empatía.

Abstract. This essay reflects on those teaching experiences that have a strong influence on students and allow teachers to grow as individuals as well as professionals. The author approaches positive affection towards students, which allows children to be emotionally well adjusted, consequently, promoting their desire to learn, attend classes, and have good social relationships with their peers, and allows teachers to have confidence and high self-esteem. Emphasis is placed on the fact that educators must treat students well, know their family environment, solve their emotional deficiencies, if any, and show empathy towards them. In short, teachers are encouraged to give priority to affective relationships in their pedagogical practice. The author also includes some experiences from her professional practices, where affection towards children was essential.

Keywords. Childhood, affection, tenderness, empathy.

1 Máster en Ciencias de la Educación con énfasis en Docencia Universitaria, posee licenciaturas en Ciencias de la Educación con énfasis en Administración Educativa de la Universidad de Costa Rica y con énfasis en Educación Preescolar de la Universidad Nacional. Laboró como asesora en el Programa de Capacitación para Administradores de la Educación del Ministerio de Educación Pública durante el periodo 1990-1994, programa para el cual escribió módulos de Instrucción en temas como Estrategias para mejorar el rendimiento académico y Fundamentos de planificación educativa, entre otros. Experiencia como directora del Centro Infantil del Instituto Nacional de Aprendizaje (CIINA). Ha laborado como académica en la Carrera de Educación Preescolar en la Unidad de Educación Básica del Centro de Investigación y Docencia en Educación de la Universidad Nacional. En la actualidad se desempeña como profesora de Educación Preescolar en la Escuela Invu Las Cañas de la Ciudad de Alajuela, Costa Rica. 
URL: http://www.una.ac.cr/educare

CORREO: educare@una.cr

Reflexión temática

Y si tuviere profecía, y entendiese todos los misterios y toda la ciencia...y no tengo amor, nada soy.

I Cor 13:2

La vida de profesionales docentes ofrece un sinnúmero de experiencias que enriquecen su quehacer y le hacen crecer como persona. Cuando en el ejercicio profesional se ha dedicado buena parte de la vida al trabajo con la niñez, además de transitar por diferentes políticas educativas, enfoques curriculares y paradigmas teóricos, se logra permear la existencia de mayor sensibilidad, tolerancia y afecto, condiciones claves que exige la niñez: ese semillero que en un futuro cercano será la ciudadanía productiva de nuestra sociedad.

Este ensayo analiza, introspectivamente, la labor pedagógica desplegada en las aulas por más de veinticinco años, y recopila diferentes experiencias que han constituido el andamiaje para el posicionamiento teórico que la autora ha logrado construir sobre el sentido de lo que significa ser docente $y$, en especial, una docente del nivel preescolar.

Como formadora de formadores, se espera que el estudiantado universitario interiorice las experiencias expuestas e impregne sus prácticas docentes de mucha afectividad hacia los niños y las niñas que atienden. Asimismo, se pretende generar inquietud en las colegas del área para que reflexionen sobre las formas en que expresan o no el afecto a los niños de sus aulas.

Toda labor, y en especial la labor docente, debe estar impregnada de amor, porque para su desarrollo, el ser humano requiere que todas sus experiencias se desenvuelvan a través de relaciones afectivas; solo así se logra optimizar el desarrollo emocional y social de los niños y las niñas de hoy. Al respecto, en el artículo Desarrollo de competencias afectivas durante la primera infancia (2002) se menciona:

El desarrollo integral de los seres humanos promovido desde la escuela cada vez cobra mayor importancia. En la sociedad moderna es común encontrar que los profesores remplazan a los padres en la formación afectiva de los niños y esta labor comienza en el preescolar. (párr. 1)

No obstante, es imperativo que tanto la familia como la institución educativa velen en forma compartida por la formación integral de la niñez. 
Por su parte Definición abc (s. f.), en lo referente a la afectividad expresa:

La afectividad, entonces, es parte fundamental de la vida porque es la que en definitivas cuentas nos ayudará a ser mejores personas y a no sentirnos jamás solos. En contrapartida, cuando este aspecto de nuestra vida no se encuentra en armonía, seguramente, nos costará mucho más crear vínculos con las personas y expresar nuestros sentimientos. (párr. 5 y 6 )

También Quindós et al. (2010, p. 35) se refieren a la afectividad como “... las necesidades de creer, de afirmarse, de amar y ser amado y de ser valorado ...", necesidades que para las autoras constituyen los motores para el desarrollo emotivo y social, entre otros.

En la medida en que se demuestre el afecto a las personas con quienes se tiene relación a diario, los individuos se sentirán más humanos y podrán establecer confianza básica y vínculos afectivos más seguros.

A menudo se recuerda con tristeza a algún profesor que nos trató como un número más de su lista de estudiantes, con quien nunca se tuvo una mirada a los ojos, un saludo o un trato cordial. Posiblemente ello nos impidió disfrutar del aprendizaje, trabajar mejor, desear aprender más y sentirnos seguros dentro del salón de clase. Durante mi época de colegiala, se escuchaba con frecuencia la expresión "la letra con sangre entra", y este era el estandarte que enarbolaban algunos de los profesores. Muchos años más tarde llegué a comprender, con base en los escritos de Pinto (2012), que las prácticas de los educadores latinoamericanos, en muchos casos estuvo impregnada de "mandonismo": Como una expresión distorsionada de la autoridad, mediante la arrogancia, la rigidez, la discriminación y la desconfianza, lograban mandar e imponer a los otros una determinada concepción de la verdad.

Por su parte, Garnier (2007. Los avances y los retos en Costa Rica, párr. 12), en una de sus conferencias, refiere al riesgo de que lograda una buena educación preescolar, la forma en que muchas veces se educa "en primaria y luego en secundaria, en vez de construir sobre las bases establecidas por el preescolar, empiezan por de-construir o destruir esas bases, para restablecer una educación asentada en el miedo, en la jerarquía y en el autoritarismo... .

Por lo tanto, es importante que en la actualidad las prácticas "mandonistas" sean enterradas, para dar paso a una enseñanza de calidad donde medie entre educador y educando la afectividad y, por qué no decirlo, la ternura.

Se debe reflexionar en las palabras que expresa Restrepo (2000): "...la caricia es fundamental para el desarrollo del niño" (p. 17). De ahí que las muestras de afectividad positiva hacia el estudiantado redundarán en su deseo de aprender, su motivación por asistir a clases, las buenas relaciones entre iguales y un buen ajuste emocional en cuanto a apego seguro y confianza básica, entre otros beneficios para su autoestima y formación integral.

La educadora y el educador de preescolar debe desempeñar con celoso afecto su labor docente, máxime si se toma en cuenta la fragilidad de los niños y niñas que acuden a las 
URL: http://www.una.ac.cr/educare

CORREO: educare@una.cr

aulas. En las intervenciones pedagógicas se deben integrar procesos de comprensión que permitan incorporar en las experiencias diarias una aceptación total de la singularidad de cada estudiante, una apertura total y una empatía sincera hacia cada uno de los infantes que se atienden en el aula.

Al respecto, Restrepo (2000) expresa con gran acierto: "...yo veo en el maestro como una especie de escultor, alguien que va esculpiendo la sensibilidad del niño" (p. 18). Por tanto, es de gran importancia la afectividad en el aula, y en especial en el aula preescolar, donde se forman las nuevas generaciones. Asimismo, Pinto (2012) afirma "...las condiciones afectivas ambientales permiten al estudiante percibir con mayor confianza su posibilidad de protagonismo" (p. 65).

El Diccionario de la Real Academia Española (s. f.) describe la afectividad como el "... conjunto de sentimientos, emociones y pasiones de una persona"; por tanto, se considera que todo el personal docente de preescolar, además de su formación académica, debe realizar un esfuerzo adicional porque su persona esté impregnada de los más nobles sentimientos hacia los niños que atiende, tales como: ternura, cariño, amor, comprensión, respeto a su individualidad, apertura para el diálogo, consideración, paciencia y tolerancia, entre otros.

La afectividad, es "un conjunto de emociones, estados de ánimo, sentimientos que impregnan los actos humanos ... incidiendo en el pensamiento, la conducta, la forma de relacionarnos, de disfrutar, de sufrir, sentir, amar, odiar e interaccionando íntimamente con la expresividad corporal, ya que el ser humano no asiste a los acontecimientos de su vida de forma neutral" (Afectividad s. f., párr. 3). Es decir, la afectividad asigna una sensación subjetiva frente a cada acontecimiento de la vida y, por tanto, constituye una orientación para las conductas de los niños y niñas, e influye en toda su personalidad (Afectividad, s. f.).

En el artículo Desarrollo de competencias afectivas durante la primera infancia (2002) se mencionan tres tipos de competencias afectivas:

Las competencias intrapersonales [las primeras] generan una relación apropiada con nosotros mismos y nos permiten el autocontrol, el dominio de emociones y conductas, el autoconocimiento para saber quiénes y cómo somos y la autovaloración para formular juicios de valor acerca de nosotros mismos... las competencias interpersonales [las segundas] nos facilitan querer, conocer e interactuar con otros. [Y por último], las competencias sociogrupales, como conocer, liderar y valorar grupos, determinan el nivel de integración social que logramos. (párr. 8) 
URL: http://www.una.ac.cr/educare CORREO: educare@una.cr

En síntesis, las competencias afectivas son:

- Competencias intrapersonales. Aquellas que le permiten a la persona una vinculación consigo misma.

- Competencias interpersonales. Aquellas que le permiten a la persona relacionarse con los otros individuos.

- Competencias sociogrupales. Aquellas que le permiten a la persona relacionarse en los grupos.

Lo anterior confirma la importancia de procurar y favorecer un ambiente propicio en las aulas, donde las competencias afectivas se vean favorecidas de modo que los niños y las niñas logren moldear las conductas para una sana convivencia dentro del salón de clases y, por qué no, trascender hasta su familia.

La afectividad en los procesos de enseñanza y de aprendizaje cobra tanta importancia, que el Ministerio de Educación Pública (MEP), en el Programa de Estudios para el Ciclo de Transición, propone la afectividad como parte del proyecto de lo que debe ser la labor educativa, además, es un ingrediente desde la perspectiva de lo que se espera que se construya y se desarrolle en el aula (MEP, 1995).

En relación con el área socioemocional, el programa sugiere:

...cada niño y niña al convivir con otras personas va interiorizando su propia imagen, conociendo sus aptitudes y limitaciones, gustos y deseos, reconociéndose diferentes de los demás y al mismo tiempo parte de un grupo. Es decir, va constituyendo su identidad que tiene connotaciones tanto positivas como negativas, agradables o conflictivas que sumada a condiciones favorables de afecto y control, le permiten tener un adecuado nivel de confianza y seguridad en sí mismo, y un mayor grado de independencia. (MEP, 1995, p. 16)

Por su parte, Piaget (citado por MEP, 1995) señala que "las emociones son el motor del aprendizaje, es así como, el desarrollo de la inteligencia no está desligado de los afectos" (p. 17). Esto confirma el hecho de que si los niños comparten sus experiencias de aprendizaje bajo un clima cálido, con mucho afecto y muestras de cariño, su aprendizaje será más efectivo y duradero.

Como se puede constatar, la afectividad no puede separarse del quehacer docente. Al respecto, Pinto (2012) expresa que: 
URL: http://www.una.ac.cr/educare

CORREO: educare@una.cr

... la centralidad de la emoción personal y la motivación colectiva en las relaciones educativas que se establecen entre educandos, entre éstos y sus docentes, entre los educadores entre sí, con sus directivos y sobre todo entre este colectivo de actores institucionales con las familias y las comunidades del entorno educativo, es otro contenido básico que debe incluirse en la educación institucionalizada ... [las] coordinaciones cognoscitivas/afectivas son características enraizadas en el colectivo escolar y en la convivencia educativa". (pp. 64, 65)

En su quehacer docente, la maestra jardinera, como solía llamarse, o quien enseñe en este nivel educativo no debe ser una educadora o educador más del gremio de la docencia; por el contrario, debe ser una persona con cualidades afectivas especiales, que asuma con verdadera entrega su rol formador de la niñez que ingresa a nuestro sistema educativo.

Como ya se mencionó, si bien en el nivel preescolar los aspectos técnicos cobran gran importancia y requieren ser planificados con sumo cuidado, el afecto que el personal docente demuestre a sus niños y niñas les marcará para el resto de sus vidas.

Al respecto, Maya (2003) expresa que el niño observa el comportamiento y las actitudes de sus docentes, y en ello se basa para construir sus propias conductas y actitudes, "...especialmente si la relación que el niño y la niña tienen con aquél o aquélla es cálida, abierta, afectuosa y tierna" (p. 107).

Es importante tener presente que los estudiantes que ingresan a las aulas provienen de diferentes contextos, en algunos casos carentes de manifestaciones de afecto, por lo que se hace necesario considerar cada una de sus realidades en forma individual, viendo, como lo expresa Maya (2003), su dimensión afectiva de ser humano, además de su educabilidad y su fragilidad, y convertirse, para cada niño, en guía, de manera que quien, lo requiera, pueda acudir en cualquier momento con confianza y seguridad de que encontrará el apoyo que necesita. Con gran acierto, Pinto (2012) considera que:

La afirmación afectiva del educando/a en la formación académica y en su reconocimiento de sujeto con capacidad de decir su palabra, va permitiendo el desarrollo de la creatividad y del aprendizaje que sabe solucionar problemas de toda índole, lo que sin duda es una posibilidad de desarrollo para la conciencia ciudadana activa del educando/a. (p. 66)

El personal docente de preescolar debe demostrar en todo momento amor por su trabajo y por todas las acciones que este lleva implícitas. Debe asumir con responsabilidad y compromiso la noble tarea de acompañar y guiar a la niñez de nuestra sociedad y reflejar en todas sus expresiones el placer que le provoca su vocación. 
A este respecto, Maya (2003) expresa: “...nosotros y muchos autores más pensamos, que no podemos quedarnos sólo allí, en la perspectiva 'de intelectuales' de los docentes, ignorando la dimensión afectiva o emocional del ser humano que también se construye y se educa..." (p. 109).

Estos pensamientos también los reafirma el MEP (1995), al declarar que la educación “... como proceso social abarca, no sólo el desarrollo de los niños y de la familia, sino además la autorrealización del educador como persona y como profesional" (p. 19).

Además, siendo los años preescolares una etapa de la vida del ser humano donde se consolidan y expanden los aprendizajes en las diferentes áreas de desarrollo, "... se requiere una estimulación apropiada, basada principalmente en el juego la interacción inteligente y creativa del adulto con el niño y viceversa" (MEP, 1995, p. 20).

También el MEP (1995) establece, con base en Jiménez (1990), algunas características personales, sociales e intelectuales necesarias para el personal docente del nivel preescolar costarricense. A continuación se mencionan algunas de ellas:

- Mantener el dominio de sí misma o de sí mismo.

- Mostrar paciencia en el trato con los niños y niñas.

- Actuar con sentido del humor.

- Facilitar un ambiente confortable entre quienes le rodean.

- Disfrutar del trato con los niños y las niñas.

- Reflexionar ante sus actividades con las demás personas.

- Criticar su comportamiento con las demás personas.

- Expresar comprensión hacia las demás personas.

- Evidenciar capacidad de aceptar críticas.

- Manifestar discreción en sus relaciones con adultos y niños.

- Respetar los valores culturales del grupo, la comunidad y el país.

- Mostrar interés de superación personal y profesional. (pp. 25-26)

Como se puede observar, son muchas las cualidades que debe poseer el personal docente de preescolar, principalmente durante su convivencia en el aula, para lograr transmitir a la niñez la alegría de vivir y la motivación necesaria para decir con certeza que esta vida merece ser vivida a plenitud. Como bien lo expresa Sequeira (2000), "...es en la convivencia social donde el ser humano se hace persona y se perfecciona como tal" (p. 71). 
URL: http://www.una.ac.cr/educare

CORREO: educare@una.cr

\section{Experiencias de vida dignas de recordar}

Como se expuso al principio del presente ensayo, durante muchas y largas jornadas de trabajo en el aula preescolar se ha logrado compartir con toda una gama de niños y de niñas y sus diferentes familias. A continuación se describen algunos casos particulares de niños que con una alta dosis de afectividad lograron disfrutar e integrarse al colectivo del aula y vivir un año preescolar lleno de experiencias significativas. Cabe agregar que los nombres que se utilizan son ficticios.

A- Josué es hijo de una madre soltera y mayor de 40 años, cuyo trabajo es salir por las calles de la comunidad a recoger chatarra y toda clase de deshechos "útiles" para ella. Durante los primeros 5 años de vida de José, su mundo y sus juguetes eran la calle y lo que su madre recogiera. Al ingresar al kinder su asombro era demasiado, pero no sabía cómo relacionarse con otros niños ni cómo interactuar con la variedad de materiales presentes en el aula. Por su parte, la madre esperaba a su hijo a la salida de clases a unos cincuenta metros del portón principal, para no acercarse a las otras madres que también recogían a sus hijos o hijas. Durante la entrevista inicial con la mamá de Josué, se logró constatar que era analfabeta, por tanto, los mensajes al hogar que se enviaban en el cuaderno de comunicaciones iban y venían sin que nadie los leyera o firmara. Ese día la afectividad me permitió tener un mayor acercamiento a esta familia, porque además de concluir con la entrevista, requisito indispensable para el expediente del niño, hicimos algunos pactos en forma oral que nos permitieron establecer una estrecha relación hogar-escuela durante todo el curso lectivo. Algunos de esos pactos fueron los siguientes:

- Expresarle que era una mamá muy valiosa y que debía acercarse al portón a encontrarse con su hijo al salir, sin importarle lo que las demás señoras dijeran o pensaran de ella.

- Como ella reconocía los números hasta el diez, yo le daría un papelito, solo con el número de entrada o de salida al kínder, cuando el horario por alguna razón especial debía cambiar.

- Además, le leería en forma personal, de ahora en adelante, cada mensaje que colocara en el cuaderno de comunicaciones.

- Su autoestima y confianza se vio fortalecida y mantuvimos una linda relación durante la estadía de Josué en el kinder, la cual se mantiene en la actualidad.

Por su parte, Josué fue motivado para que usara los juguetes o materiales con confianza, y se estimuló al resto del grupo para que lo integraran en sus juegos. En el área cognitiva y de lenguaje, José manifiesta su falta de estímulo durante su infancia temprana, pero en las áreas 
psicomotriz y afectiva es un niño dulce, que se ha ganado el cariño de sus maestras de primaria. Repitió su primer grado, cursó el segundo y actualmente cursa su tercer grado.

Es muy gratificante y sencillo acercarse a las personas que requieren un trato diferente, para que el proceso de aprendizaje y la estadía de su hijo en la institución educativa sean más placenteros. Es muy satisfactorio servir a quien necesita recibir el cariño sincero. Así, la madre de Josué supo corresponder a mi afecto, ya que en el día de las madres me llevó un par de chayotes, regalo que agradecí más que si hubiese sido comprado en una tienda reconocida. Se cumple así el refrán de que las pequeñas cosas hacen más bella la vida. Y todavía, la mamá de Josué sigue halando leña y diferentes objetos de las calles y llevándolas a su humilde rancho del precario, pero cuando me ve en las afueras del kinder, detiene su carretón para expresar en alta voz y con una amplia sonrisa “Cómo le va, niña Carmen?"

B- David llegó a mi kinder ya iniciado el curso lectivo. Venía de otra escuela, en donde la docente le indicó a su madre que el niño no estaba preparado para iniciar un primer grado y sería mejor trasladarlo a preescolar para que cursara de nuevo otro año de transición. De acuerdo con lo expresado por la mamá, la indisciplina y rebeldía de David no le permitieron integrarse a la enseñanza formal. En mi primer encuentro con David, me puse de cuclillas para dirigirme a sus ojos, nos saludamos, pero él casi no contestó porque evadía la mirada, lo pasé adelante y lo senté sobre mi escritorio y le dije en tono muy enfático: "... a partir de hoy, yo voy a ser tu amiga, pero usted no se va a portar mal como dice su mamá, porque en este kinder todos los niños son muy bien portados, ¿de acuerdo?".

David levantó su mirada y me ofreció una leve sonrisa. Los primeros días fueron de acomodo, él desafiando mi autoridad, dejaba los materiales sin ordenar y juntos los ordenábamos, cuando yo le estiraba mi mano para que la tomara, él se tapaba la cara porque creía que mi mano estirada era para agredirle, ya que así lo hacía su mamá. Le recordaba que yo era su amiga y que lo amaba, hasta que poco a poco fue cambiando su rebeldía, aunque se mostraba agresivo con sus iguales. En junio, David había tenido un gran avance en su disciplina, aunque su mamá manifestaba que en la casa era igual. Pero David vivía en dos ambientes y sabía bien cómo actuar en cada uno: con sus amigos en el kinder amigable y confiado, y con su mamá en la casa rebelde por el trato que recibía. Después de vacaciones de medio período fue traslado a otra escuela y no se supo más de él, pero con este caso pude comprobar la importancia de la afectividad dentro del aula.

C- Adrián es un niño con síndrome de Down que desde la edad de un año fue atendido en una escuela de enseñanza especial. Al cumplir los cinco años es referido para ser integrado a una escuela regular. Cuando lo matriculan en mi institución, la persona encargada de la matrícula escribe fuera de su expediente: "ojo, síndrome de Down". Cuando la administración de la escuela reúne a las docentes de preescolar para repartir la matrícula comenta que hay un 
URL: http://www.una.ac.cr/educare

CORREO: educare@una.cr

niño con síndrome de Down, y que lo va a rifar para ver a quién le corresponde. Al escuchar esa expresión mi corazón dio un vuelco y me embargaron una serie de sentimientos positivos, e inmediatamente dije: "...no lo rife, él no es una mercancía para ser rifado, yo me lo dejo". El resto de las compañeras respiraron hondo y desde ese momento yo asumí con todo mi afecto ese reto. Para ello, primero di gracias a Dios por haberme prestado un hijo sano, o al menos con una buena división de cromosomas. Y luego, como madre, pensé en la mamá de Adrián y en toda su ilusión porque su hijo se integraría a una escuela regular.

A partir de ahí, busqué bibliografía sobre las características de estos niños y me preparé para recibirlo con gran entusiasmo, como se inicia todo curso lectivo. Adrián se integró con facilidad al grupo, participaba bastante conforme a sus posibilidades y el resto de niños y niñas lo aceptaron completamente, por sus limitaciones de lenguaje le tarareaba las canciones del kinder a su mamá y realizaba la expresión corporal de cada canción. Adrián disfrutó mucho su año de transición y aprendió a compartir y a convivir con otros niños. La mamá de Adrián se mostraba muy satisfecha con los pequeños grandes logros que notaba en su hijo. Como docente, me sentí muy gratificada porque Adrián nunca significó un niño problema dentro del grupo, sino que, por el contrario, me permitió conocerlo y aumentar mis capacidades tanto afectivas como profesionales. Además, Adrián ofreció una hermosa experiencia de vida para todas sus compañeras y compañeros, quienes aprendieron a darle su afecto y a compartir con él todos los juegos y actividades.

\section{Reflexiones finales}

Como se puede observar, resulta imperativa la afectividad en el aula preescolar, más aún si se considera que este nivel constituye la base de la estructura del sistema educativo, porque en la medida en que los niños se sienten respetados y queridos por sus docentes, así será su interés por aprender y su motivación por asistir a su centro de estudios. El personal docente de este nivel debe impregnar su quehacer pedagógico de mucho afecto y ternura, pues solo así logrará en sus estudiantes un buen ajuste emocional, una mejor salud mental y buenas relaciones sociales tanto con sus iguales como con la misma persona docente.

Por otra parte, el personal docente debe establecer empatía con cada uno de los niños y niñas de su grupo y conocer la situación familiar, con el propósito de crear en su aula el ambiente propicio donde se viva el amor y la hermandad, que en muchas ocasiones están ausentes en el núcleo familiar, y son tan importantes en esta etapa de sus vidas en que están en formación sus valores y actitudes.

Por la experiencia de la autora, se puede agregar que es muy satisfactorio crear junto a los niños un ambiente de armonía dentro de la sala de clase, donde todos se sientan motivados a llegar cada día no solo para aprender, sino también para expresar su afecto a cada integrante de la comunidad educativa. 
Esto enriquece día con día la vida de quien se ejerza la educación, además de que fortalece su vocación y le llena de energía para seguir compartiendo el afecto con tantos niños y niñas que año tras año pasan por las aulas. Y, con el paso de los muchos años, la vida permite encontrarnos en otros ámbitos con jóvenes que nos saludan y nos abrazan con el mismo afecto y ternura que compartían en el aula preescolar.

Queda claro, entonces, que la práctica profesional del personal docente de preescolar deja abierto el espacio para valorar no solo los contenidos programáticos, sino también las emociones y los sentimientos, como parte fundamental de la atención integral de los estudiantes. Es así como el aula preescolar se presta para incorporar, de manera intencional, la afectividad y la ternura como motor fundamental para el aprendizaje.

De esta forma, se hace viva la palabra de Dios en mi desempeño como persona y como profesional, cuando en la carta a los Colosenses también nos sugiere a los hombres y mujeres del presente siglo: "Y todo lo que hagáis, hacedlo de corazón, como para el Señor y no para los hombres" (Colosenses 3: 23).

\section{Referencias}

Afectividad (s. f.). Divulgación, 12. Recuperado de http://matap.dmae.upm.es/cienciaficcion/ DIVULGACION/12/AFECTIVIDAD.html

Definición abc. (s. f.). Definición de afectividad. Recuperado de http://www.definicionabc.com/ social/afectividad.php

Desarrollo de competencias afectivas durante la primera infancia. (2002). Bogotá: Secretaría de Educación del Distrito. Recuperado de http://educinicialvenezuela.blogspot. com/2012/02/desarrollo-de-competencias-afectivas.html

Garnier, L. (2007). Aprender de preescolar. San José: Costa Rica: Asesoría de Preescolar, MEP. Recuperado de http://www.leonardogarnier.com/articles/mep-subversivo/aprender-depreescolar-635

Maya, A. (2003). Conceptos básicos para una pedagogía de la ternura. Bogotá: Ecoe Ediciones.

Ministerio de Educación Pública. (MEP). (1995). Educación preescolar: Ciclo de transición. Nuevos programas que se aplicarán a partir de 1996. San José, Costa Rica: Autor. Recuperado de http://controlmasproducciones.com/educatewp/wp-content/uploads/2013/04/ programa-de-transicion.pdf 
URL: http://www.una.ac.cr/educare

CORREO: educare@una.cr

Pinto, R. (2012). Principios filosóficos y epistemológicos del ser docente. San José, Costa Rica: CECC/ SICA. Recuperado de http://www.universidadfutura.org/wp-content/uploads/2012/10/ principios-filosoficos-y-epistemologicos-de-ser-docente.pdf

Quindós, M., Rodríguez, L., Cundíns, S., Rodríguez, C., Novoa, B., Rocha, N. ... Muíños, F. (2010). El desarrollo del niño/a de 0 a 6 años. Lexington KY: Lulupres-Incorporate.

Real Academia Española. (s. f.). Diccionario de la lengua española. Recuperado de http://www. rae.es

Restrepo, L. C. (2000). La pedagogía de la ternura en la educación primaria. Educación. Revista de la Universidad de Costa Rica, 24 (especial), 11-23.

Sequeira, A. (2000). Un enfoque para la educación y la escuela del nuevo siglo. Educación. Revista de la Universidad de Costa Rica, 24 (especial), 65-73.

\section{Cómo citar este artículo en APA:}

Villalobos, C. M. (enero-abril, 2014). La afectividad en el aula preescolar: Reflexiones desde la práctica profesional docente. Revista Electrónica Educare, 18(1), 303-314. Recuperado de http://www.revistas.una.ac.cr/index.php/EDUCARE/issue/current

Nota: Para citar este artículo en otros sistemas puede consultar el hipervínculo "Como citar el artículo" en la barra derecha de nuestro sitio web:

http://www.revistas.una.ac.cr/index.php/EDUCARE/index 